\title{
Pescadores artesanales y prácticas pesqueras a inicios del siglo XX. Entre el control estatal y la libertad de pesca
}

\section{Artisanal fishermen and fishing practices at the beginning of the $20^{\text {th }}$ century. Between state control and freedom of fishing}

\author{
Pablo Camus Gayán ${ }^{1}$ https://orcid.org/0000-0002-9705-6320 \\ Mauricio Arias ${ }^{2}$ https://orcid.org/0000-0003-2022-5314 \\ ${ }^{1}$ Pontificia Universidad Católica de Chile, Instituto de Historia, Santiago, CHILE. \\ Email: pcamusg@uc.cl \\ ${ }^{2}$ Pontificia Universidad Católica de Chile, Centro de Políticas Públicas, Santiago, CHILE. \\ Email: moarias@uc.cl
}

\section{Resumen}

Este artículo busca evidenciar cómo el Estado fue delimitando y prohibiendo algunas prácticas de pesca artesanal a comienzo del siglo XX, con el fin de proteger los recursos marinos considerando principios racionales y de conservacionismo, y en beneficio del erario nacional, cambiando la lógica de bienes comunes y libertad de pesca. Así, este artículo plantea que tras la promulgación de la Ley de Pesca de 1907 en Chile, se inició tanto un proceso de apropiación fiscal y cercamiento de los espacios y bienes comunes litorales y marinos como también un proceso de intervención del Estado en las prácticas de los pescadores artesanales, especialmente en qué, cómo y cuándo pescar. Esta intervención cambió radicalmente las prácticas de la pesca artesanal y la relación del hombre con el mar durante las primeras décadas del siglo XX.

Palabras claves: pesca artesanal, control estatal, pescadores, libertad de pesca, prácticas pesqueras, Ley de Pesca.

\begin{abstract}
This article seeks to show how the State was delimiting and prohibiting some artisanal fishing practices in the early twentieth century, in order to protect marine resources under rational principles and conservationism for the benefit of the national treasury, changing the logic of common property and freedom fishing. Thus, this article states that after the enactment of the Fisheries Act of 1907 in Chile, both a process of fiscal appropriation and enclosure of coastal and marine common spaces and goods was initiated, as well as a process of State intervention in practices of artisanal fishers, especially in what, how and when to fish. This intervention radically changed the practices of artisanal fishing and the relationship between man and the sea during the first decades of the 20th century.
\end{abstract}

Keywords: artisanal fishing, state control, fishermen, freedom of fishing, fishing practices, Fisheries Act.

Recibido: 17 julio 2017. Aceptado: 24 septiembre 2018 


\section{Introducción}

Las primeras décadas del siglo XX son un período crucial para entender la pesca artesanal en Chile, así como las prácticas de pesca utilizadas por los pescadores en las costas del país, pero sobre todo es un período fundamental para entender la relación del hombre con el mar y cómo el Estado jugó un papel determinante en su futura configuración.

Hasta la promulgación de la Ley de Pesca de 1907, el mar fue considerado como un bien común, por lo que los pescadores artesanales tenían derecho no solo a acceder a los recursos del mar, sino también a hacer uso de las playas y franjas litorales de la costa para sus actividades pesqueras, independiente de quien fuera el propietario de ellas. Pese a que la idea del bien común generó una serie de conflictos entre pescadores artesanales y propietarios - por la disputa entre el derecho a la libertad de pesca versus el de propiedad-, con la entrada en vigencia de la Ley de Pesca esta idea comenzó a mutar a que el mar y sus recursos eran propiedades del Estado, susceptibles de ser usados y comercializados en sus términos y condiciones.

Así, el período entre 1907 y 1931 es fundamental para visibilizar y evidenciar cambios trascendentales y permanentes para las prácticas de los pescadores artesanales, ya que, en definitiva, con la Ley de Pesca se inicia un proceso de "cercamiento" de los bienes comunes litorales y marinos. Este cambio de paradigma se explica en gran medida por la introducción de nuevos conceptos al imaginario estatal, como la racionalidad, la conservación de los recursos naturales y la regulación de las actividades económicas, entre otros argumentos utilizados en la época.

De esta manera, la apropiación fiscal e intervención del Estado de los recursos marinos, tanto en la pesca artesanal como industrial, fue en función de un mejor aprovechamiento de la actividad pesquera, según la normativa creada y la opinión de los propios funcionarios e instituciones públicas encargados de hacerla cumplir. En suma, la Ley de Pesca de 1907 y el cambio de paradigma por parte del Estado sobre los bienes marinos y litorales significaron profundos e irreversibles cambios para las prácticas pesqueras de los pescadores artesanales, sobre todo en qué, cómo y cuándo estos debían pescar. La relación de los pescadores artesanales con el mar-principalmente económica- ya no dependería de una decisión personal, o la de un grupo determinado de ellos, sino que de una decisión estatal que se manifestaba a través de leyes, decretos, reglamentos o vedas que, al mismo tiempo, representaban otro imaginario sobre la pesca.

En este sentido, lo que plantea este trabajo es que tras la promulgación de la Ley de Pesca de 1907 no solo se inicia un proceso de cercamiento y apropiación fiscal de los espacios y bienes comunes litorales y marinos, sino también un proceso de intervención del Estado en las prácticas de los pescadores artesanales. Esta mediación cambia radicalmente las prácticas de la pesca artesanal y la relación del hombre con el mar en las primeras décadas del siglo XX, ya que más allá del cambio de paradigma, lo que se transforma son las dinámicas del hombre con el mar en sus diferentes dimensiones, ya sean económicas, sociales, culturales y funcionales.

El Estado comienza progresivamente a delimitar qué prácticas de pesca son más apropiadas que otras, en aras de legislar sobre cómo deben pescar los pescadores artesanales. Como fundamento legal se erige la figura del Presidente de la República y su potestad para decidir sobre los recursos marinos, en tanto estatales, mientras que en paralelo se inicia una búsqueda progresiva de una mayor eficiencia para beneficiar el erario nacional. Así, es el Estado el que define cómo se debe pescar y busca eliminar prácticas de pesca artesanal como la pesca con vara y con dinamita. Incluso está dispuesto a realizar demostraciones y clases para "educar" a los pescadores.

El Estado además incorporó la noción de que es necesario conservar los recursos medioambientales, por lo que instaura mayores restricciones en aras de preservarlos principalmente a través de las vedas. Así, no solo define cómo pescar, sino también qué y cuándo los pescadores artesanales debían hacerlo, cambiando la lógica de libertad de pesca que existía antes de la Ley de Pesca de 1907. Este período se extiende hasta 1931, ya que con la promulgación del DFL 210 se transfiere la tuición legal de la costa a 
la Armada, iniciándose un proceso de militarización del espacio que afectó a los pescadores artesanales y sus prácticas.

Los trabajos históricos relacionados con el mar se han enfocado más en los sucesos epopéyicos o catastróficos. Sin embargo, no se ha abordado lo suficiente su estudio desde una perspectiva que considere las interacciones entre los distintos actores involucrados en la explotación de los recursos marinos y las consecuencias e impactos de la modernización capitalista y de sus modos de acumulación en los ecosistemas y en las relaciones de producción. En esta perspectiva, la definición y naturaleza del régimen de propiedad de los recursos económicos contenidos en los océanos es un problema fundamental. El mar depende de equilibrios biológicos muy dinámicos y en este los peces se desplazan libremente y sin dueńo alguno, por lo que se trata de un tipo de recurso único al momento de definir derechos de propiedad. En teoría, se ha planteado que debido a la imposibilidad de asegurar su posesión los distintos actores tienden a sobreexplotar el recurso. Tomando un caso similar como las praderas de pastoreo, Garrett Hardin (1968) señaló que de "la libertad de los recursos comunes resulta la ruina para todos". Lo más probable era que cada usuario de pastos introduciría más animales para obtener más beneficios, generando una competencia desenfrenada que llevaría a la sobreexplotación y agotamiento de las praderas.

Planteada originalmente en 1833 por el economista británico William Forster Lloyd, la idea de que la "propiedad de todos es propiedad de nadie" fue retomada a mediados del siglo XX por H. Scott Gordon (1954) y A. D. Scott (1955), quienes postularon que solo cuando se era propietario de un bien se producía un verdadero incentivo para conservarlo de manera eficiente, proponiendo un régimen de propiedad privada o, bien, de propiedad del Estado. Esta tesis fue relevada como ley por los economistas y permitió justificar soluciones a problemas ambientales mediante mecanismos de mercado, lo cual se ha expresado, por ejemplo, en la privatización de los océanos. Conceptos como 'sobrecapacidad', 'sobreexplotación' y 'sobrepesca' serían claves para comprender el abrumador predominio de los enfoques privatizadores en relación con la gestión de los ecosistemas y de los recursos marinos (Mansfield, 2004; March, 2012).

No obstante, han surgido cuestionamientos. La crítica central es que propiedad común no es lo mismo que inexistencia de propiedad o de mecanismos de control. Históricamente las comunidades han constituido una amplia gama de instituciones y normas para regular y limitar el uso de los recursos comunes. Elinor Ostrom (1990) estableció que los seres humanos interactuaban a fin de mantener en el largo plazo los niveles de producción de los recursos comunes. El historiador Edward Palmer Thompson sugirió que esta teoría era ignorante, pues daba por sentado que las tierras comunales eran "pastos abiertos a todos". Los hechos contradecían la teoría, ya que "a lo largo del tiempo y del espacio los usuarios de tierras comunales han creado una rica variedad de instituciones y sanciones comunitarias que han frenado y limitado el uso". A su juicio, "a pesar de su aire de sensatez, lo que el argumento pasa por alto es que los commoners mismos no carecían de sentido común" (Thompson, 1995 pp. 127-129). David Harvey (2004) sitúa la privatización de los bienes comunes dentro de lógica de la acumulación originaria estudiada por Karl Marx en El capital y acuña el concepto "acumulación por desposesión". En esta perspectiva, la estatización y posterior privatización del mar puede ser mirada como un proceso de despojo y de acumulación por desposesión. La Ley de Pesca de 1907 inició este ciclo histórico por medio del cual a través de siglo XX los pescadores artesanales fueron perdiendo su autonomía y su libre acceso a los recursos marítimos y costeros (Camus, Hidalgo y Muńoz, 2016).

En relación con los materiales y métodos, la construcción de este trabajo se basa en la investigación de los fondos documentales resguardados en el Archivo Nacional de Chile. Esta metodología nos ha permitido -con todas las dificultades conocidas-, acceder a las políticas estatales, pero también a la voz e inquietudes de aquellos que ante una progresiva marginación acudieron a los mecanismos de mediación estatales como estrategia para seguir ocupando, utilizando y explotando los espacios marítimos y costeros. Con la ayuda de estas fuentes inéditas y desconocidas esperamos contribuir a la comprensión de las relaciones humanas con los ecosistemas 
marítimos y costeros, entendiendo todo aquello como un conjunto complejo de interacciones entre actores humanos y no humanos.

\section{De la pesca con vara a la introducción del buceo}

A partir de la promulgación de la Ley de Pesca de 1907, el Estado chileno comenzó progresivamente el cercamiento de los mares y sus recursos, entendiendo que estos pertenecían al Estado y que, como tal, el presidente de la República poseía el derecho a legislar sobre ellos. Para aprovechar estos recursos, se procedió a diferenciar entre prácticas de pesca más apropiadas para los fines gubernamentales de explotación racional y conservación del medio ambiente y aquellas que atentaban contra estos objetivos porque resultaban nocivas para los consumidores, o porque no eran completamente eficientes y/o generaban estragos en el ecosistema acuático. De esta manera, las reglamentaciones y modificaciones que acompañaron esta ley fueron regulando y dictaminando en la práctica el modo en que debían pescar los pescadores artesanales, rechazando métodos antiguos como el uso de la vara o candelero y la dinamita, propiciando nuevas prácticas como bucear para mariscar o el uso de lazos y rastras.

En el primer caso, la pesca con vara o candelero consistía en la utilización de un aparato con lanzas de punta metálica, o de madera, la que al ser introducida al mar permitía capturar diversas especies de mariscos, especialmente choros. Al evaluar el uso de la vara o candelero, encontramos que durante el período estudiado su penalización fue conflictiva en muchos aspectos.

Por ejemplo, en el puerto de Corral y lugares vecinos, los pescadores rechazaron el reglamento sobre pesca de choros de 1910, ya que les prohibía el uso de la vara o candelero, y durante años trataron de negociar con las autoridades estatales para revocar el decreto o aplazar su entrada en vigor. Así, en marzo de 1911, 62 miembros del gremio de pescadores de choros de Corral firmaron una solicitud dirigida al gobernador marítimo de Valdivia, dando cuenta de la petición previa que habían realizado al Ministerio de Industria y Obras Públicas respecto a derogar el reglamento o, en su defecto, aplazar en cinco años su aplicación. Le pedían que atendiera a sus necesidades económicas y al hecho de que la concesión pedida al ministro iba, según ellos, a ser aprobada para que les permitiera de momento seguir practicando la pesca con vara. En sus palabras:

Desde largos años atrás, Señor Director, disfrutábamos de la prerrogativa de pesca de choros y luego de un solo golpe se nos priva de ella, y junto con ella, del pan que podemos y debemos adquirir para nuestros hijos. También apreciará U.S. la imposibilidad en que nos encontramos, debido a nuestra crítica situación pecuniaria, para adquirir máquinas de lazos y sus útiles para dar comienzo a la pesca; esto sólo podrán hacerlo las personas de recursos, mientras nosotros los proletarios, vemos alejarse los medios indispensables para nuestro sustento. ${ }^{1}$

Sin embargo, luego de tres meses de esta solicitud, los pescadores volvieron a acudir a las autoridades pues no hubo una buena acogida. Esta vez aducían que la situación de pobreza era más apremiante ante el cierre de la empresa siderúrgica de Altos Hornos, "el único establecimiento de importancia que existía en este pueblo" y que era fuente de trabajo para muchos pobladores. Además, según estos, la mayoría de las industrias de Valdivia también se encontraban estancadas o paralizadas en sus operaciones.

La respuesta gubernamental en este caso fue la creación de una comisión que verificara la conveniencia de mantener o no el uso de la vara o candelero. Para ello, autoridades marítimas de la Sección de Aguas y Bosques, empresarios y un delegado del gremio de pescadores de choros de Corral fueron llamados a participar en el comité.

En este sentido, en noviembre de 1911, el inspector general de Bosques, Pesca y Caza, Federico Albert, daba cuenta de su visita a la isla Santa María a raíz de la comisión del ministro de Industria y Obras

1 Nueva solicitud de pesca con vara por cierre de siderúrgica en Corral. Archivo Nacional de Chile, Ministerio de Industria y Obras Públicas, 30 de julio, 1911, Vol. 2253, f. 437. 
Públicas para evaluar esta situación junto a otro comité que se formó en la zona. En su informe realizó una detallada evaluación de las condiciones para la pesquería en el área y las posibles propuestas de concesiones de los bancos de choros, pero principalmente se enfocó en denostar el uso del candelero:

En nuestras investigaciones, pudimos comprobar en primera línea, por la estracción de gran número de conchas quebradas de choros, que los bancos abundantísimos en épocas pasadas, se encuentran hoy en gran parte destruidos a causa de la pesca con candelero. [...] los pescadores quedaron plenamente convencidos que al pescar con candelero se aprovecha solo la cuarta o quinta parte del choro que se destruye, i que por consiguiente debe prohibirse absolutamente el uso de este aparato, estableciendo penas i multas para los pescadores que lo usen en lo futuro. En cambio merece nuestra mejor recomendación para la estracción de los choros, cholgas, ostras i erizos, el buzo por cuanto es el sistema mas conveniente. Si bien es verdad que la adquisición de una máquina para buzo importa un gasto de $\$ 2.000$ mas o ménos, también es cierto que en 15 minutos el buzo puede estraer un saco de moluscos, mientras que con candelero se necesita de un día entero para reunir la misma cantidad i se destruye lastimosamente una enorme cantidad de animales. ${ }^{2}$

Para Albert la necesidad de demostrar científicamente la ineficiencia del uso del candelero o vara (Figura 1) y sus nefastas consecuencias era claramente una prioridad de su trabajo. Por ello, el enfoque está en entender que la inversión en equipos de buceo es, a mediano y largo plazo, una necesidad evidente a pesar de que los pescadores no contaran con los fondos necesarios. Resalta entonces el beneficio económico y de tiempo de pesca que conlleva su uso, junto con evidenciar el destrozo que genera en los bancos de choros de la zona, incluso con recursos fotográficos.

2 Viaje de Federico Albert a Isla Santa María. Archivo Nacional de Chile, Ministerio de Industria y Obras Públicas, 29 de noviembre, 1911, Vol. 2448, f. 57.

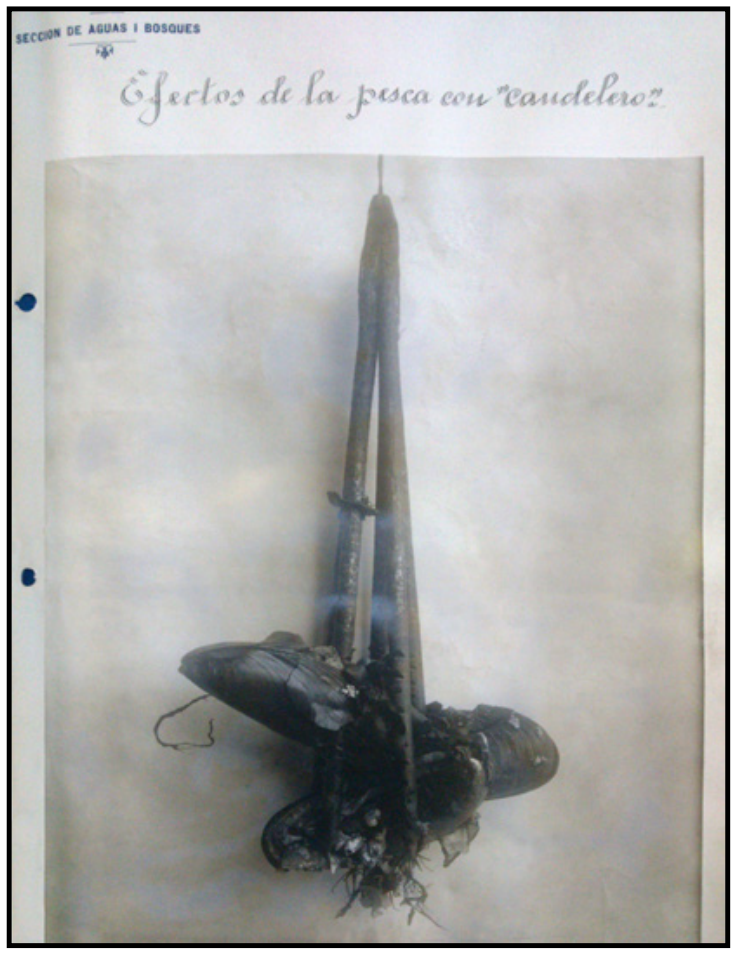

Figura 1. Fotografía de un candelero tomada durante la expedición de Federico Albert en la isla Santa María.

En otro documento de similar tenor y destinatario, Albert enumera todos los bancos de choros del país que han sido completamente agotados debido a esta práctica pesquera, además de recalcar que "no existe ningún país en el cual se permita el uso del candelero", y que el gobierno tiene "la obligación moral" de velar por la conservación de sus recursos marinos para las generaciones venideras. ${ }^{3}$ Así también, en respuesta al diputado Sr. Manuel Gallardo en abril de 1912, hace hincapié en los problemas infecciosos y de comercialización que conlleva tener choros heridos por el candelero y el detalle técnico de la superioridad del buceo para mariscar, "diez veces superior en rendimiento a la pesca con candelero". ${ }^{4}$

Las acusaciones hacia Federico Albert y las autoridades marítimas respecto a la prohibición fueron

3 Solicitud para pescar choros con candelero o vara. Archivo Nacional de Chile, Ministerio de Industria y Obras Públicas, 6 de mayo, 1912, Vol. 2448, f. 51.

4 Solicitud para pescar choros con candelero o vara. Archivo Nacional de Chile, Ministerio de Industria y Obras Públicas, 6 de mayo, 1912, Vol. 2448, f. 53. 
duras durante este período. Para los pescadores, la situación significaba grandes carencias y la inevitable hambruna de ellos y sus familias dada la "hostilización" de su trabajo. Ante esto, Albert apelaba a que "los servicios administrativos de Pesca del Ministerio de Industria" los ayudaban en muchos aspectos, y que en efecto los pescadores "deben en muchas partes su amparo cuando han sido desalojados ú hostilizados por Sociedades e Industriales, á las gestiones de este servicio". Tras detallar su apoyo en primas para la pesca, arrendamiento de playas y demases, prosigue enfatizando que "se trata de resguardarles bienes que ellos mismos pretenden destruir i de cuya conservación, depende el pan de ellos i de sus familias, no solo en el presente sino en el futuro". ${ }^{5}$ Finalmente, si es que los pescadores no quisieran adaptarse a las medidas de conservación, Albert argumentaba que existían muchas industrias necesitando de mano de obra que gustosamente podrían recibirlos.

Sin embargo, a pesar del rechazo de Albert al uso de la vara o candelero, su férrea resolución va a amainar poco después, tras una nueva solicitud de los pescadores de Corral. En esta ocasión, los pescadores revelan su extrañeza ante la prohibición del uso de la "vara armada de palillos", es decir, de madera, pues "la experiencia de sesenta años de pesca nos comprueba que el procedimiento de la vara armada no perjudica en absoluto la procreación i que, por el contrario, la multiplicación es normal y abundante". Además, prosiguen, la rastra recomendada también deja choros en el fondo marino que inevitablemente morirían al cabo de ocho días.

A pesar de que Albert desestima inicialmente esta objeción, tras volver a evaluar la situación decide adoptar nuevas medidas. En primer lugar, en julio de 1912 solicita al ministro de Industria y Obras Públicas una disposición conciliadora entre las demandas de los pescadores y el reglamento vigente, considerando que el uso de escafandra para el buceo suponía un peligro para quien no sabía utilizarla apropiadamente, para lo cual indicó:

5 Solicitud para pescar choros con candelero o vara. Archivo Nacional de Chile, Ministerio de Industria y Obras Públicas, 6 de mayo, 1912, Vol. 2448, f. 56.
Propongo á su consideración el nombramiento de un Guarda-Pesca de primera clase, puesto que sería servido por un buzo competente en las faenas de la extracción de choros y al que se le señalaría residencia en Corral. De hacerse este nombramiento soy de opinión que se encomiende al expresado funcionario la tarea de enseńar gratuitamente al gremio de pescadores de Corral, ajustándose al libro de matrícula que posee la gobernación marítima de aquel puerto, el uso prudente y metódico de la escafandra, para lo cual se le dotaría de dos aparatos equipados con sus elementos complementarios. ${ }^{6}$

Estas clases gratuitas de buceo para los pescadores de Corral pretendían ser un aporte desde el Estado para el progresivo cambio de las prácticas pesqueras en favor de una metodología más racional y proclive a la conservación de los recursos marinos. En otros lugares, como en los puertos de Talcahuano y Arauco, se habían producido buenos resultados con estas medidas. Sin embargo, en Corral al parecer no fueron suficientes, pues en abril de 1913 Albert vuelve a reflexionar sobre el estado de la situación y considera que la evidencia recogida muestra que

[...] el candelero o vara hecho totalmente de madera i que se emplea en la actualidad por los pescadores de Corral, no ofrece los gravísimos inconvenientes que tiene el mismo aparato cuando está hecho de fierro o de otra sustancia metálica. En consecuencia opino porque se aclare el artículo segundo del Reglamento de pesca de choros aprobado por decreto $\mathrm{n}^{\circ} 1346$ de 8 de julio de 1910 en el sentido de que se deje establecido que el aparato prohibido por el Gobierno es el candelero o vara de puntas metálicas. ${ }^{7}$

6 Clases de buceo para pescadores de Corral. Archivo Nacional de Chile, Ministerio de Industria y Obras Públicas, 30 de julio, 1918, Vol. 2448, f. 224.

7 Autorización de extracción de choros con vara con punta de madera. Archivo Nacional de Chile, Ministerio de Industria y Obras Públicas, 16 de abril, 1913, Vol. 2518, $\sin$ folio (s.f.). 
Vemos así, finalmente, cómo las autoridades estatales actúan como agentes mediadores entre las disposiciones regulatorias pesqueras y los pescadores artesanales. La pregunta latente en el caso expuesto está en qué metodología se muestra como la más apropiada para la pesca siguiendo los principios expuestos por la Inspección General de Bosques, Pesca y Caza en sus documentos, es decir, de explotación racional y de conservación de las especies marítimas como propias del Estado. En esta controvertida discusión, los pescadores sienten que las prohibiciones impuestas respecto al uso de la vara o candelero no los consideran a ellos, sometiéndolos al hambre y arriesgando su forma de vida al no poseer los recursos económicos suficientes para pescar según lo recomendado por el gobierno, es decir, con el uso de escafandras y de lazos o rastras.

Desde la Inspección, Federico Albert se convierte en la autoridad visible que media en esta situación, buscando soluciones conciliadoras tras un inicial rechazo a toda negociación. Surgen así las clases gratuitas de buceo y, finalmente, la modificación al decreto que antes impedía la pesca con vara de madera, modificaciones validadas científicamente. De esta manera, si bien el Estado empieza a tener mayor injerencia en el modo en que los pescadores deben desarrollar sus faenas pesqueras, busca también mediar dentro de cierto esquema de racionalidad y conservacionismo para cimentar una nueva etapa de control estatal y regulación de la libertad de pesca.

\section{Eliminando la pesca con dinamita}

$\mathrm{Al}$ igual que la pesca con vara o candelabro, la pesca con dinamita constituyó una práctica muy extendida entre los pescadores artesanales, incluso con la venia indirecta de las autoridades locales. Esta representó tanto un peligro físico para los involucrados en su uso como un método ineficiente para pescar y nocivo para el medio ambiente. A pesar de que ya había sido prohibida por ley el 6 de julio de 1898, no fue sino hasta después de la promulgación de la Ley de Pesca de 1907 que se comenzaron a denunciar y a sancionar los casos a medida que el Estado fue enviando a sus emisarios a fiscalizar por todo el territorio nacional.
Esta situación la podemos ver claramente en el caso del norte de Chile, en donde la expedición del Sr. Luis Rivera, de la sección de Fomento de Pesquería, dio cuenta de lo extendido que era el uso de dinamita en la pesca local. De acuerdo al informe presentado por este en agosto de 1920, dice el director general de los Servicios Agrícolas:

El Señor Rivera deja constancia en esa comunicación de que en todos los puertos por él visitados se espenden peces capturados por medio de la dinamita, lo que pone en evidencia de que, tanto las autoridades civiles como marítimas, hacen caso omiso de lo dispuesto en el artículo 52 del Reglamento de Pesca, que prohíbe la captura de peces por medio de explosivos. Hai puertos como Tal Tal y Chañaral en donde se pesca a vista i paciencia de las autoridades locales, las que acostumbradas a ver este sistema de pesca lo han llegado a considerar casi como un medio racional para capturar los peces. El pez dinamitado se descompone muchísimo mas lijero que los que han sido capturados con redes o anzuelos; i, como lo manifiesta mui bien el funcionario informante, el uso de esta perniciosa práctica ha acarreado como consecuencia la disminucion del comercio de peces frescos que ántes se internaban desde el puerto de Arica a los mercados bolivianos. ${ }^{8}$

Así, según se infiere del documento, el rechazo a esta práctica apunta a la "racionalidad" de la que carece, pues en muchos sentidos resulta nociva e improductiva. Por una parte, el período de frescura del pescado es menor frente al uso de otras técnicas de pesca, y por lo tanto genera la disminución de posibilidades de comerciar con zonas más alejadas al punto de extracción. Incluso, se podrían generar problemas por intoxicación dado el estado de descomposición del pescado. Además, la técnica implicaba la destrucción de bancos y criaderos de peces y mariscos, lo cual atentaba contra los intereses del Estado de velar por la conservación de sus recursos y la misma rentabilidad de estos a mediano y largo plazo.

8 Viaje a los puertos y caletas al norte de Coquimbo. Archivo Nacional de Chile, Ministerio de Industria y Obras Públicas, 26 de agosto, 1920, Vol. 2990 (s.f.). 
Estos elementos son denunciados, también, en otros casos en donde se acusa el uso de dinamita. Incluso las nuevas inversiones del Estado en especies exóticas se ven en peligro ante esta técnica, como lo fue el caso del salmón. Tras su introducción al país de manera precaria, los huevos fueron depositados en ciertos ríos y lagunas del sur de Chile a fin de que se reprodujeran libremente. Sin embargo, en noviembre de 1907, el inspector de Enseńanza y Fomento Agrícola daba cuenta de que

[1] as constantes informaciones que se reciben confirman la persistente batida que se hace a los salmones echados a diversos ríos del país corriéndose el riesgo de acabar con ellos si no se toman severas medidas que los protejan i que se evite el que sean pescados antes que su reproducción esté asegurada. Entre los medios empleados para pescarlos figura frecuentemente la dinamita $\mathrm{i}$ aunque la ley de fecha 6 de julio de 1898 $\mathrm{n}^{\circ} 1050$, pena con una multa de $\$ 50$ a $\$ 500$, este criminal sistema de pesca su empleo es frecuente i casos ha habido perfectamente comprobados en que alcaldes de Comunas encargados por la ley de Municipalidades de todo lo relativo a la caza i pesca, han sido sorprendidos haciendo uso de ella por simple pasatiempo.?

Posteriormente, en el comunicado se sugiere la prohibición total de la pesca durante dos a tres ańos en ciertos ríos del sur, a fin de dejar en manos del gobierno el verdadero resguardo de la pesquería. Se sugiere, además, una suerte de denunciabilidad premiada en donde las multas se repartirían en partes iguales entre el denunciante, la municipalidad de la respectiva comuna y el Fisco. Esto, a fin de que existiera un real incentivo para la vigilancia de los ríos entre las autoridades y otros civiles. La confianza en las autoridades locales claramente es cuestionada, pues no ha sido sino hasta después de la promulgación de la Ley de Pesca de 1907 (y bajo la autoridad de una sección del Ministerio de Industrias y Obras Públicas) que se ha puesto relevancia en la sanción

9 Prohibición de pesca con dinamita. Archivo Nacional de Chile, Ministerio de Industria y Obras Públicas, 19 de noviembre, 1907, Vol. 2158, f. 15. de las leyes que penan la pesca con dinamita o cualquier tipo de explosivo.

Este caso ilustra así la necesidad de que el gobierno se involucrara con mayor peso en la aplicación de la ley, a fin de resguardar los intereses del Estado respecto a la pesca y cómo, además, la captura con dinamita revelaba una suerte de complicidad entre los pescadores y las autoridades locales -al hacer los primeros caso omiso de lo estipulado en la ley y permitiéndolo los segundos, motivados por interesas particulares.

Sin embargo, este no fue siempre el caso. En la zona de Lota, Coronel y San Vicente se generó una fuerte disputa dadas las supuestas falsas acusaciones del guardapesca de Santa María hacia los pescadores artesanales, denunciando que estos pescaban con dinamita en los bancos de choros de la isla Santa María.

Así, el guardapesca Mario Mardones aducía en febrero de 1916 que desde hacía un mes y medio habían arribado numerosas embarcaciones que pescaban con este medio ilegítimo en la isla, y que no había podido expulsarlas por las groserías y balazos con que era recibido, además de que estaban amparados por el subdelegado civil y la fuerza de Carabineros. La carta al gobernador marítimo de Talcahuano decía, además, que

[...] la pesca con dinamita y en cualquier forma en el puerto Sur está destruyendo completamente los bancos de choros que el Gobierno desea a toda costa conservar, instrucciones dadas por la Gobernación Marítima al infrascrito lo facultaban para tomar todas las medidas necesarias tendentes al resguardo de el banco de choros, el Guarda Pesca infrascrito propuso como medida indispensable el prohibir el acceso a las playas de ese puerto y la pesca en los mares de el mismo, medida que fue aceptada por el antecesor de U.S., pero es el caso que esto no se [cumple] y vienen diariamente innumerables embarcaciones que no respetan orden [alguna]. ${ }^{10}$

10 Conflicto en isla Santa María. Archivo Nacional de Chile, Ministerio de Industria y Obras Públicas. 1 de febrero, 1916, Vol. 2733 (s.f.). 
Pedía, entonces, que se suspendiera todo permiso para ir a pescar al puerto Sur ya emitido o por emitirse, y que el alcalde de mar de la isla, Sr. Simón Home, notificara a "los pescadores venidos de los puertos indicados la cancelación de sus respectivos permisos y la orden de abandonar las playas indicadas en el plazo de 24 horas bajo pena de multa". ${ }^{11}$ Esta solicitud fue acogida y sancionada por decreto bajo la premisa de que se alineaba con las disposiciones previas del exconcesionario del banco de choros de la isla, Sr. José Farto, para proteger el área de la sobreexplotación y también los intereses del Estado en la zona.

Sin embargo, los pescadores replicaron en una carta del 13 de marzo de 1916 que dichas denuncias eran injurias "pues, jamás se ha cometido, tanto por los pescadores de San Vicente, Coronel y Lota, y aún de la misma isla, la pesca con dinamita ni con ninguno de los elementos que usamos para nuestra industria encima de los bancos de choros". ${ }^{12}$ Más aún, para estos el verdadero problema estaba en el guardapesca de la isla, quien buscaba limpiar su imagen ante las autoridades pues sabía que lo habrían de cambiar de puesto a la brevedad.

Junto a esta declaración, los pescadores fueron apoyados por el diputado de Talcahuano Sr. Coveña, defendiendo su derecho a pescar en esa zona tras el término del contrato con el anterior arrendatario y de sus cláusulas protectoras. Igualmente desde la Inspección General de Bosques, Pesca y Caza se consideró que el decreto debía ser anulado, ya que la Gobernación Marítima había sobrepasado sus atribuciones para reglamentar la pesca en la zona. Así también el director general de Servicios Agrícolas apoyó la legalidad de esta causa en su comunicado al ministro de Industrias y Obras Públicas, quien acogió estas réplicas favorablemente.

De esta manera, la disyuntiva a nivel institucional revela la activa tensión entre permitir a los pescadores el libre ejercicio de la pesca y la regulación

11 Conflicto en isla Santa María. Archivo Nacional de Chile (ANCh), Ministerio de Industria y Obras Públicas, 1 de febrero, 1916, Vol. 2733 (s.f.).

12 Pescadores de San Vicente. Archivo Nacional de Chile (ANCh), Ministerio de Industria y Obras Públicas, 13 de marzo, 1916, Vol. 2448 (s.f.). de los recursos marítimos estatales, en este caso en concesión a arrendatarios. Al vencer el contrato, lo que rige con precedencia es el derecho a la libertad de pesca, susceptible de ser modificado nuevamente con la entrada en vigor de un nuevo contrato de arrendamiento de los bancos de choros.

En este caso en particular, la pesca con dinamita se torna en una acusación que agrava la falta cometida por la pesca clandestina y, nuevamente, apela a la racionalidad de la que carece. Tanto así que surge la amenaza de la erradicación de los pescadores de ciertos puertos como si fueran un estorbo. Y aunque la denuncia sobre la pesca con dinamita no es resuelta finalmente, son las atribuciones legales del gobierno sancionadas por la Ley de Pesca de 1907 las que terminan dictando la suerte de los pescadores, protegiéndolos de la arbitrariedad.

La acusación del uso de dinamita puede entonces ser vista como un agravante importante de connotación social durante este período estudiado, más allá de tratarse de una violación a la reglamentación de la pesquería vigente. En esta misma zona de Coronel y Lota se produjo, en noviembre de 1921, la acusación de parte de la Dirección General de los Servicios Agrícolas por la pesca con dinamita realizada por los mineros del carbón, "especialmente los días Domingo casi siempre con el manifiesto propósito de producir la alarma pública, ya que no se nota intención ni trabajo alguno de recoger el pescado dinamitado". ${ }^{13}$ Esta denuncia prosigue con el incordio que esto supone para los pescadores profesionales, pues

[a] los perjuicios que se ocasionan con este método de captura en la fauna marítima de la localidad ya que el pescado herido muere pronto y se pierde, se agrega casi siempre la interrupción forzosa de la labor del pescador profesional, quien vé entorpecidas sus faenas por la escasez de la producción pesquera que sobreviene invariablemente del uso repetido de las materias esplosivas. Los pescadores de

13 Denuncia pesca con dinamita, así como de disparos a pescadores en Lota y Coronel. Archivo Nacional de Chile (ANCh), Ministerio de Industria y Obras Públicas, 21 de noviembre, 1921, Vol. 3217, f. 721. 
la región, esponiendo estos acontecimientos, han agregado, además, que cuando van a mariscar a los bancos que las mareas descubren mui cerca del faro de Lota, han sido ahuyentados por disparos que provienen de las vecindades, sin que les haya sido posible hasta ahora precisar con exactitud su procedencia ni identificar a los culpables. ${ }^{14}$

Desde la Gobernación de Lautaro se adujo que los disturbios ocurrieron durante las huelgas de marzo y abril de ese año, y que posteriormente se produjeron hechos aislados de similar tenor "en parajes donde no puede ejercerse vigilancia, ni menos precisar a sus autores, i por consiguiente, imposible de evitarlo". Asimismo desestimaron la acusación respecto a los disparos, pues los pescadores no habrían hecho la denuncia a la autoridad marítima correspondiente para su investigación. De esta manera, se cierra el caso aludiendo a una situación difícil de regular y las autoridades locales se desmarcan de un resguardo más efectivo. En cuanto a la pesca con dinamita, se muestra cómo los pescadores no tienen relación alguna con esta técnica y acusan su uso a personas ajenas al gremio, que buscan más bien una connotación de protesta y desorden público con esta práctica.

Sin embargo, a pesar de que en el caso anterior los pescadores se desentienden de su potencial relación con el uso de la dinamita, esta continuó siendo una práctica muy extendida durante el período estudiado, ocasionando graves accidentes, y que incluso se extendió por lo menos hasta mediados del siglo XX. En el norte de Chile existen numerosas denuncias en esta época que atestiguan dicha aseveración. Por ejemplo, en 1920 fueron detenidos en la bahía de Coquimbo los pescadores Juan Ramos y Juan Cortés, luego de que ciertos trabajadores de la casa del Sr. J. J. Mac-Auliffe los viesen pescando de tal modo pasado la medianoche. ${ }^{15}$

14 Denuncia pesca con dinamita, así como de disparos a pescadores en Lota y Coronel. Archivo Nacional de Chile (ANCh), Ministerio de Industrias y Obras Públicas, 21 de noviembre, 1921, Vol. 3217, f. 721.

15 Juan Ramos y Juan Cortés. Pesca con dinamita. Juzgado de Letras de Coquimbo, $\mathrm{N}^{\circ}$ de Caja $520, \mathrm{~N}^{\circ}$ de Expediente 21, 19.02.1920 / 30.08.1921.
Solo dos años antes en la misma zona se había reportado la muerte de Juan Meneses, quien tras fallar un tiro de dinamita que le explotó en la mano murió irremediablemente mientras pescaba junto a su colega Manuel Vega. El peligro humano que reportaba el uso de la dinamita no había sido previsto, e incluso el pescador Manuel Vega rechazó que fuese una práctica usual entre él y su compañero, pese a las evidencias. ${ }^{16}$ De igual manera, la pesca con explosivos se realizó ampliamente en el sector de Antofagasta, incluso hasta los años cincuenta, como lo atestigua el caso de la sustracción de explosivos destinados a la pesca con dinamita a los pescadores Juan de Dios Espinoza y José Segundo Tabilo en 1957. Estos también quisieron infructuosamente desentenderse del hallazgo, pero fueron sentenciados con pena de cárcel o multa según la reglamentación vigente. ${ }^{17}$

De esta manera, progresivamente, se fue afianzando la labor estatal de sancionar la pesca con dinamita. Si bien en un inicio el diagnóstico era apabullador, dada la extensión de dicha práctica con la anuencia de las autoridades locales, diversos organismos estatales como la Dirección General de Servicios Agrícolas, la Inspección General de Bosques, Pesca y Caza y el Ministerio de Industria y Obras Públicas fueron sancionando los casos según se ameritaba.

Para ello, los distintos reglamentos y modificaciones a la Ley de Pesca de 1907 fueron claves en la atribución de poderes y penas por cada violación a la ley. Incluso se reveló una cierta connotación de violencia y disrupción social ligada a la dinamita, de la cual los pescadores quisieron desentenderse. En último término, la problemática respecto al uso de dinamita muestra las dinámicas sobre la disputa de atribuciones entre entidades estatales y también entre la prevalencia de la libertad de pesca o el control estatal en la regulación de la pesquería.

16 Alfredo Meneses. Sobre accidente en pesca con explosivos, Juzgado de Letras de Coquimbo, $\mathrm{N}^{\circ}$ de Caja 487, $\mathrm{N}^{\circ}$ de Expediente 12, 11.07.1918 / 12.09.1918.

17 Maldonado Tabilo, José Segundo con Espinoza Juan de Dios. Sustracción de explosivos destinados a la pesca con dinamita, Juzgado del Crimen de Antofagasta, Caja $N^{\circ}$ 41221, Número de Expediente 17, 22.11.1957 / 30.04.1958. 


\section{Vedas pesqueras y control estatal}

Desde la promulgación de la Ley de Pesca de 1907, y a través de los reglamentos y modificaciones asociadas que le siguieron, el Estado chileno no solo se atribuyó el derecho a regular las metodologías empleadas en las faenas pesqueras artesanales, sino que implementó una serie de vedas y restricciones a la extracción de pescados y mariscos asociadas a ciertos períodos, en aras de su conservación como recursos estatales. Para hacer efectiva esta regulación, diferentes empleados públicos e instituciones estatales extendieron su presencia a lo largo del país, sin importar la lejanía o dificultad de acceso a estos territorios.

Un caso decidor corresponde a la expedición que realizó el inspector de Fomento de Pesquería, Sr. Luis Rivera M., a petición del ministro de Industria y Obras Públicas, para que diera a conocer en los puertos de Coquimbo y hacia el norte del país la ley y reglamento de fomento a la pesquería vigentes en 1920. Según el informe de Rivera, no solo es la extendida pesca con dinamita una gran falta a la ley, según vimos con anterioridad, sino que la "ignorancia cabal" y "dejadez" frente a las normativas estatales son generalizadas en los puertos visitados entre Arica y Coquimbo. En sus palabras:

He podido notar que en ninguna de las localidades inspeccionadas los pescadores conocían las citadas disposiciones y que las autoridades encargadas de aplicarlas en algunos lugares no las conocían y en otros desentendíanse de ellas por errores de interpretación. Mi visita ha puesto término a esta situación. $^{18}$

Acto seguido, dio cuenta de cómo los gremios de pescadores se interiorizaron de los beneficios que las primas de fomento a la pesquería podían otorgarles y cómo acceder a ellas, al igual que "se habilitaron los puertos de Mejillones, Taltal y Chañaral no comprendidos en el artículo 22 del reglamento". ${ }^{19}$

18 Viaje a los puertos y caletas al norte de Coquimbo. Archivo Nacional de Chile, Ministerio de Industria y Obras Públicas, 26 de agosto, 1920, Vol. 2990 (s.f.).

19 Viaje a los puertos y caletas al norte de Coquimbo.
Elementos necesarios para la recaudación monetaria fiscal fueron distribuidos en los Registros de Aduanas que lo requerían respecto a los derechos de extracción de choros, cholgas y erizos de mar, los cuales previamente no se cobraban y que significarían un cuantioso aumento para las arcas fiscales. Rivera, además, instó a las autoridades aduaneras a denunciar las infracciones a la ley y a seguir las debidas instrucciones para inspeccionar la mercancía. En definitiva, tras estas medidas regulatorias, Rivera aseguraba al final de su informe el convencimiento de que "cesarán o se reducirán considerablemente muchos de los abusos y errores que hasta aquí se han cometido y aumentarán en apreciable proporción las entradas por recaudación de derechos de pesca". ${ }^{20}$

Esta intención estatal de vigilar y castigar en conformidad a la ley, al mismo tiempo que se incrementaban los recursos monetarios estatales, se extendió a otros puntos más alejados del territorio, como lo fueron los mares australes. En esta zona el problema estaba en regular con éxito la caza de ciertas especies marinas para evitar la clandestinidad y asegurar que se cumplieran las vedas estipuladas. Allí se había practicado con anterioridad la veda de caza de lobos marinos, nutrias y chungungos entre los meses de noviembre y febrero a través de una ordenanza emitida en $1892 .{ }^{21}$ Esta medida buscaba proteger dichas especies y evitar la intensa sobreexplotación a la que estaban expuestos a causa de los barcos ingleses y estadounidenses que aprovechaban de cazar indiscriminadamente, sobre todo en las loberías del país. Frente a estas necesidades y a las nuevas disposiciones reglamentarias por ejecutarse, el inspector general de Bosques, Pesca y Caza, Federico Albert, expresaba al ministro de Industrias y Obras Públicas en 1912

[...] la conveniencia de solicitar al Ministerio de Marina, por conducto del de Industria, se ordene a la Dirección General de la Armada ponga á disposición de la Inspección General

Archivo Nacional de Chile, Ministerio de Industria y Obras Públicas, 26 de agosto, 1920, Vol. 2990 (s.f.).

20 Viaje a los puertos y caletas al norte de Coquimbo. Archivo Nacional de Chile, Ministerio de Industria y Obras Públicas, 26 de agosto, 1920, Vol. 2990 (s.f.).

21 La reglamentación de la caza y pesca de lobos marinos. Archivo Nacional de Chile, Ministerio de Industria y Obras Públicas, 1900, Vol. 1697 (s.f.). 
dos escampavías, elijiéndolos entre los más rápidos y convenientemente armados (uno ó dos pequeños cañones de tiro rápido o bien ametralladoras) á fin de poder dar caza é imponerse, entre otros, á los veloces clippers norte-americanos, que son los que más darán que hacer en las regiones australes.

Al hacer este pedido, y para prevenir una posible negativa de la Superioridad Naval, que podrá alegar escasez de barcos, como lo hizo al pedir la abrogación de la ordenanza de 1892 sobre caza de lobos y nutrias, convendrá hacer presente que á la fecha están terminadas o por terminar las grandes campañas de levantamientos hidrográficos de Chiloé y de la costa exterior de los canales patagónicos, que ocupaban desde años atrás media docena de escampavías. ${ }^{22}$

Esta medida pretendía no solo asegurar definitivamente una policía marítima que velara por los intereses del Estado en la protección de dichas especies, sino que además extender el conocimiento estatal sobre el territorio al encargárseles "establecer un rejistro de las loberías de lobos comunes y finos, regiones balleneras y bancos de choros y ostras, levantando croquis provisionales de los bancos que descubran" para su correcta inspección. Los exiguos recursos estatales serían así mejor aprovechados. De esta manera, las vedas, los registros, la policía marítima responden todos a un afán del Estado de reglamentar la libertad de pesca en aras de la conservación y explotación regulada de los recursos marinos.

En otro sector de difícil acceso y regulación, como lo es el lago Llanquihue, el nuevo Reglamento de Pesca de 1916 generó controversias locales respecto a la ampliación de las vedas y a la implantación de un derecho de extracción de ostras y mariscos. El lugareño Liborio Sánchez se quejaba en una carta al ministro de Industrias y Obras Públicas sobre el dinero comprometido en la paralización de las actividades pesqueras en tiempo de veda y del incordio

22 Solicitud de dos escampavías para controlar caza de lobos y ballenas. Archivo Nacional de Chile, Ministerio de Industria y Obras Públicas, 29 de mayo, 1918, Vol. 2448, f. 81. que suponía para los pescadores artesanales dicha medida. Más aún, Sánchez cuestionó la validez del decreto arguyendo que sus prohibiciones

\section{[...] dispararan [...] contra toda esta creación} esforzada i costosa de negocios i de bienestar alimenticio, i la destruyen desde su vieja base: la libertad de pesca que no es justo ni limitar ni derogar, que ninguna conveniencia hai en atacar, i que por el contrario todo aconseja protejer i estimular con la mas alta actividad del Estado i la mas influyente de sus enerjias. ${ }^{23}$

Prosigue considerando que la excusa de la conservación constituye un mero "fantasma" frente a la abundancia de mariscos en la zona y que "el Gobierno no puede políticamente llevar tan lejos su paternalidad" sin un consejo científico adecuado y que, de todas maneras, "las prohibiciones del decreto son perfectamente invijilables y serán contrabandeadas por el hambre que es el más acucioso de los contrabandistas". ${ }^{24}$

Frente a esta petición, el ministro de Industrias y Obras Públicas Ángel Guarello reafirmó la implementación del nuevo reglamento, enfatizando que este reemplazaba al anterior ya caduco de 1907, y que los nuevos impuestos solo se abocaban a dos tipos de mariscos, a fin de aumentar los escasos recursos fiscales. Al mismo tiempo, Guarello resaltó los beneficios que traía la crianza artificial de ciertos mariscos y pescados y de cómo esta no se vería afectada por la veda y por tanto reportaría mayores beneficios económicos a largo plazo. El ministro, además, defendió el interés por la conveniencia pública y el resguardo de los recursos detrás de la implementación de las vedas, nombrando casos en los cuales los bancos de choros y ostras habían sido agotados por la falta de protección, y que lo mismo sucedería en el lago Llanquihue. ${ }^{25}$

23 Prohibición de pesca afecta a pobladores. Archivo $\mathrm{Na}$ cional de Chile, Ministerio de Industria y Obras Públicas. 31 de marzo, 1916, Vol. 2733, f. 267.

24 Prohibición de pesca afecta a pobladores. Archivo Nacional de Chile, Ministerio de Industria y Obras Públicas. 31 de marzo, 1916, Vol. 2733, f. 269.

25 Prohibición de pesca afecta a pobladores. Archivo Nacional de Chile, Ministerio de Industria y Obras Públicas, 31 de marzo, 1916, Vol. f. 2733. 
En este caso, la extensión de la presencia estatal resulta controvertida en su aplicación e incluso en su origen legal es contestada por un lugareńo. La autoridad de la ley basada en los poderes presidenciales no pareciera ser suficiente para contrarrestar o balancear la noción de libertad de pesca. El argumento de la conservación de las especies no logra tomar un peso suficiente que acredite la extensión de las medidas de veda, pues se pone en tela de juicio qué tan científica es dicha disposición estatal. Sin embargo, al mismo tiempo que se irá abriendo paso al control estatal, progresivamente los fundamentos biológicos irán tomando mayor protagonismo e incluso se utilizarán para la interpretación y discusión de ciertas medidas reglamentarias sobre la pesca, apelando también a los resquicios legales.

El caso de la pesca de erizos de mar en Valparaíso durante la veda es ejemplar en este sentido. A fecha del 9 de febrero de 1917, los capitanes de los vapores Don Luis y San Antonio elevaron una solicitud al ministro de Industrias y Obras Públicas, a fin de otorgarles el permiso para vender erizos de mar en tiempo de veda, ya que esta especie no se encontraba estipulada dentro de las prohibidas legalmente. La disyuntiva se originó con la negativa inicial de la Dirección de Sanidad de la Municipalidad de Valparaíso, alegando un "olvido" involuntario de los encargados en la redacción del reglamento. Sin embargo, desde la Inspección General de Bosques, Pesca y Caza se rebatía este argumento especificando que

[h]a sido impracticable poder prohibir la venta i el espendio de este animal porque la época de su propagación corresponde a la en que posee su mas alto valor alimenticio [...]. Por tal motivo, vedar la pesca i el espendio del erizo de mar en este preciso periodo de su vida equivaldría a reducir su consumo solo al periodo de primavera i de verano i al proceder de esta manera no habría argumento o razón de carácter biolojico para asi establecerlo, tanto mas cuanto que el publico se priva espontáneamente de consumirlo a causa de que sus "lenguas" se encuentran muy poco desarrolladas y no tienen buen sabor. ${ }^{26}$

26 Venta de erizo en tiempo de veda. Archivo Nacional de Chile, Ministerio de Industria y Obras Públicas, 9 de
Más aún, a juicio del inspector, el erizo de mar "por sus hábitos biolójicos se encuentra de por sí amparado de los efectos de una pesca inmoderada", ya que solamente vive en los fondos azotados por el oleaje, de manera que es muy difícil su captura y el resguardo que tiene lo protege de la sobreexplotación. Se pide, finalmente, que la Ordenanza Municipal que prohíbe temporalmente el expendio de los mariscos se ajuste a las disposiciones del Reglamento de Pesca del 29 de marzo de 1916.

Desde el Ministerio de Industrias y Obras Públicas se acogió favorablemente esta petición; sin embargo, tanto la Comisión de Higiene como la Dirección de Sanidad municipales desestimaron el informe del funcionario de la Dirección de Bosques, Caza y Pesca y convinieron en que dada la falta de claridad y especificidad de la ley de veda no era apropiado innovar en el tema. Firmaron para ello un proyecto de acuerdo en una sesión extraordinaria de las comisiones municipales el 6 de noviembre de 1917. Tras este revés, pero sin desalentarse, los capitanes de los vapores pesqueros volvieron a elevar una solicitud para revocar dicha decisión, apelando al poder del ministro. Esta vez, el tono de réplica fue mucho más severo. Apelando a la Ley de Pesca de 1907, el ministro hizo énfasis en que

[...] el inciso $2^{\circ}$ del artículo $6^{\circ}$ de la misma ley 1949, derogó en lo que fuere contrario a ella, lo dispuesto en la ley de Organización y Atribuciones de las Municipalidades de 22 de diciembre de 1891, dejando al Gobierno la facultad de reglamentar todo lo relacionado con la industria pesquera [...]. En el caso de acordarse por la I. Municipalidad mantener la disposición de su Ordenanza de 1903 que motiva este oficio, se verá el Ministerio en la obligación de entablar ante el Excmo. Consejo de Estado la respectiva contienda de competencia. ${ }^{27}$

Esta disputa ilustra cómo los pescadores utilizaban las disposiciones de la ley para su beneficio, y así

febrero, 1917, Vol. 2804, (s.f.).

27 Venta de erizo en tiempo de veda. Archivo Nacional de Chile, Ministerio de Industria y Obras Públicas, 9 de febrero, 1917, Vol. 2804 (s.f.). 
tratar de sortear las regulaciones y prohibiciones de pesca sin que menguara su forma de ganarse la vida. Esto incluso generó disputas entre instituciones del Estado, como en el caso de la Municipalidad de Valparaíso con el Ministerio de Industrias y Obras Públicas o entre el subdelegado de la Guardia Civil y el guardapesca en la isla Santa María, sobre quién tenía las atribuciones para regular la actividad pesquera.

En los lugares en que la precariedad tuvo mayor presencia, como en los mares australes o en el archipiélago Juan Fernández, las vedas fueron contestadas incluso con mayor ahínco a través de cartas y solicitudes que buscaban una modificación afín a los intereses del solicitante. En el caso de Juan Fernández, la prohibición de la pesca de la langosta fue durante años motivo de disputa entre los empresarios de la Sociedad de Pesca Recart y Doniez y diferentes entidades estatales pues, entre otros asuntos, acrecentaba la precariedad económica en la que se encontraba la isla. Previo a esta negociación, ya existían antecedentes de una escasez de víveres para la población en 1909. ${ }^{28}$ En ese entonces, se solicitó eliminar la prohibición de la caza de cabras debido a que el buque contratado por el Estado para traer estos insumos básicos había dejado de funcionar hacía ya dos años, y a raíz de la inestabilidad generada la situación era deplorable.

En 1913, tras la visita del inspector general de Bosques, Pesca y Caza, Federico Albert, la Dirección General de la Armada solicitó la veda de la langosta durante dos años, como medida para evitar la extinción de esta especie. Albert fue aún más tajante al especificar que la actual veda entre los meses de octubre y diciembre no había sido vigilada y que incluso desequilibraba el ecosistema, pues al disminuir la pesca del bacalao por falta de interés, su población aumentaba y se alimentaba de las larvas de langosta. Propone, así, la extensión de la zona de prohibición de caza de la langosta para dar descanso absoluto y permitir la reproducción del animal. Además, suspender la pesca por el resto del año y multar fuertemente a quienes la capturen o comer-

28 Solicitud de caza de cabras por la falta de alimentos y veda en Juan Fernández. Archivo Nacional de Chile, Ministerio de Industria y Obras Públicas, 17 de diciembre, 1909, Vol. 2253, f. 2. cialicen. No se incluía en esta prohibición la pesca para el consumo local. ${ }^{29}$

Tras divulgarse este informe en la prensa, la empresa Recart y Doniez escribió para contradecir al documento. Desde la Sociedad de Pesca arguyeron que el inspector estaba mal informado y que la situación descrita era completamente diferente. A su entender, el aumento en la venta del crustáceo se debía a las mejoras en sus navíos y técnicas de pesca, cuidando que las hembras fuesen devueltas al mar para asegurar la reproducción de la especie; si la veda no había funcionado era, entonces, debido a que otros se aprovechaban de esta circunstancia y a que la guardia marítima no era vigilante como debía. Más aún:

Exajera grandemente el Señor Inspector al tildar de abusiva la estraccion de la langosta, como cuando afirma que esta escasea; preguntaríamos al Señor Inspector en que se funda para asegurar tal cosa o de donde ha tomado datos para formarse esa opinión? [...] en una palabra, pretende sin razón alguna por este medio arruinar nuestra industria i arrastrar con ella a la ruina también a los habitantes de la isla en su totalidad pescadores que no tienen otro medio de existencia que el que les proporciona la pesca de la langosta. ${ }^{30}$

Pese a esta réplica, el decreto del 10 de marzo de 1913 sancionó la propuesta de Albert y no fue sino hasta agosto de 1919 que resurgió la problemática. Desde la Dirección General de los Servicios Agrícolas se evidenció la necesidad de una investigación profunda que acreditara las modificaciones adecuadas al caso. Así, en enero de 1920, provisoriamente se suspendió la prohibición de pesca de langostas hembras, en espera de los resultados de las pesquisas biológicas. Recart y Doniez elevaron una solicitud a la Dirección General de la Armada pidiendo que se

29 Prohibición de pesca de langostas por dos años en Juan Fernández. Archivo Nacional de Chile, Ministerio de Obras y Obras Públicas, 3 de enero, 1913, Vol. 2518 (s.f.).

30 Prohibición de pesca de langostas por dos años en Juan Fernández. Archivo Nacional de Chile, Ministerio de Industria y Obras Públicas, 3 de enero, 1913, Vol. 2518 (s.f.). 
cambiara la prohibición de caza y especificase que solo estaban comprendidas las hembras con ovas. Aprovecharon también de quejarse por el despoblamiento de la isla que la disminución de la pesca de la langosta había generado, pues

[e]ste deplorable resultado a desanimado por completo a nuestros pescadores, que a pesar de recibir un salario tres veces mayor que el que pagábamos en años anteriores, no llegaban a ganar lo suficiente para su subsistencia i la de sus numerosos hijos i muchos de ellos han resuelto abandonar la isla; en la actualidad hay tres familias que están en este puerto $\mathrm{i}$ otras dos nos han pedido pasage para venirse al continente. Si este estado de cosas continua, la isla tendra que despoblarse y todos sus habitantes emigraran teniendo que abandonar todos sus bienes acumulados de muchos años de duro trabajo i sacrificios. ${ }^{31}$

Finalmente, tras una acuciosa inspección, se reveló que la veda establecida entre el 1 de octubre y el 31 de diciembre no correspondía a la época de desove, por lo cual se modificó para el período entre el 1 de junio y el 31 de agosto, y se gravó la extracción de la langosta en 40 centavos la pieza, entre otras numerosas sugerencias. Además, se incentivó el repoblamiento del archipiélago isla de Juan Fernández con pescadores tanto nacionales como extranjeros. ${ }^{32}$ Así, las medidas propuestas buscaban con urgencia repoblar y sostener la economía de la isla, tan desgastada por la veda anterior.

En este caso vemos, en definitiva, la confluencia de varios de los factores que hemos analizado previamente sobre la presencia estatal a raíz de las vedas. En primer lugar, pese a la distancia geográfica y al aislamiento de facto que se produce en Juan Fernández, el Estado logra abrirse paso y pronunciarse progresivamente sobre el acontecer pesquero de la isla: tí-

31 Grave situación por prohibición de pescar langostas hembras en Juan Fernández. Archivo Nacional de Chile, Ministerio de Industria y Obras Públicas, 16 de agosto, 1919, Vol. 2990 (s.f.).

32 Condiciones de la Isla Juan Fernández. Archivo Nacional de Chile, Ministerio de Industria y Obras Públicas, 23 de septiembre, 1922, Vol. 3190 (s.f.). midamente (e ineficientemente) primero a través de un buque y el representante designado de la Armada; luego con la presencia de inspectores realizando expediciones científicas; fortaleciendo la cadena de comunicación y finalmente mediante la resolución de los conflictos de manera legal.

Además, es posible rastrear cómo los pescadores de la isla se encuentran directamente afectados por la veda impuesta, y de qué manera la precariedad del lugar los obliga a buscar un mejor futuro en territorio continental. Es por ello que, además de las otras razones ya señaladas, se precipitan las medidas para modificar la veda según sea necesario, sin dejar de lado un enfoque conservacionista, clave en el período analizado. Así, el Estado se va abriendo paso definiendo qué y cuándo se debe pescar, cambiando progresivamente la lógica de que el mar y sus productos son bienes comunes y que existe, en efecto, libertad para pescar.

\section{Conclusión}

Después de la promulgación de la Ley de Pesca de 1907, el acto de ir a pescar ya no dependía exclusivamente de la voluntad y la decisión de un pescador artesanal en particular, o de un grupo de ellos. La pesca, ya fuera artesanal o industrial, comenzó a ser regulada y mediada por el Estado, basada en principios racionales y científicos, según la propia definición estatal de la época. Con la entrada en vigencia de esta ley se inicia un proceso de "cercamiento" de los bienes comunes litorales y marinos, debido a la apropiación fiscal e intervención del Estado en la pesca para su mejor aprovechamiento. Esto trajo muchos cambios a las prácticas de los pescadores artesanales, especialmente sobre qué, cómo y cuándo estos debían pescar. En definitiva, esta intervención modifica radicalmente las prácticas de la pesca artesanal y la relación del hombre con el mar en las primeras décadas del siglo XX.

El cambio en la relación del hombre y el mar se muestra de manera muy patente en el caso de la pesca con vara o candelero. Esta práctica, arraigada en los pescadores artesanales por lo menos durante los últimos 60 ańos antes de ser sancionada, evidencia la progresiva injerencia del Estado en la forma en 
que debían pescar los pescadores, no arbitrariamente, sino por medio de un sustento científico y racional que supuestamente lo avalaba. En primer lugar, se trata de la poca eficiencia de la vara o candelero en comparación al buceo o la pesca con rastra, ya que desde las instituciones gubernamentales se enfatizaba en la rapidez y el aumento de la cantidad de mariscos capturados al pescar con escafandra, por ejemplo. Asimismo, se argumentaba respecto a la escasa conservación de los bancos de mariscos e, incluso, su extinción por la pesca con vara o candelero. Estos principios estatales de racionalidad y conservación no solo quedaron expuestos en la teoría, sino también en la práctica, sobre todo con la visita de Federico Albert a la isla Santa María, lo que demuestra el interés que tenía el Estado por cambiar las costumbres y prácticas de los pescadores artesanales.

A diferencia de la pesca con vara o candelero, sobre la que existió una cierta negociación o discusión argumentativa entre las distintas partes involucradas, la pesca con dinamita fue prohibida por el Estado de manera tajante. Si bien este método se encontraba arraigado culturalmente y se realizaba en distintos puntos con cierta frecuencia, se pretendía eliminar completamente su ejercicio. Más allá de su discutible eficacia al momento de la captura de ejemplares marinos, el gobierno buscaba evitar el peligro de muerte de los pescadores que suponía su uso. Al mismo tiempo, no se trataba solo de asegurar el bienestar de estos, sino también de suprimir la dinamita como práctica y herramienta de protesta asociada a los pescadores.

La injerencia estatal no solo se ocupó de cómo se debía pescar, sino también del qué y cuándo hacerlo. Este control tomó principalmente la forma de vedas pesqueras, que venían a complementar y especificar las leyes, reglamentos y decretos vigentes. Debido a que las autoridades públicas comenzaron a tomar un rol más activo y presente en los distintos puntos del país, el cumplimiento de las vedas y su sanción a través de multas y penas de cárcel implicaron la adaptación de las prácticas de pesca artesanal a este nuevo escenario legislativo. Los pescadores reconocieron la nueva dinámica estatal y procuraron sumarse a sus reglas, utilizando conductos legales para resolver sus solicitudes y quejas, entendiendo que la legislación que conllevó la Ley de Pesca de 1907 ge- neraría grandes cambios en su relación con el mar. Este proceso de adaptabilidad se evidencia en los resquicios legales y subterfugios que utilizaron para interpretar las leyes según su conveniencia, aunque en la mayoría de los casos las vedas que decretaba el Estado se cumplían.

A raíz del cambio de las prácticas de pesca artesanal, podemos ver que la relación del hombre con su medio marítimo dio paso irremediablemente a una nueva dinámica. La adaptabilidad que enfrentaron los pescadores artesanales a la intervención estatal fue el primer paso de un proceso mucho más largo y complejo que vivieron a lo largo del siglo XX. Esto porque desde 1931 se enfrentaron a un proceso de militarización del medio marino y costero por la transferencia de la tuición legal a la jurisdicción de la Armada, y es en ese contexto en que esta institución define quién puede o no estar y ocupar dichos espacios. Así, ya desde 1907 el Estado empieza a regular las prácticas de los pescadores artesanales respecto a las formas y tiempos, para luego introducir la idea de cuál es el perfil apropiado y deseado para los pescadores. Esto se evidencia a principios del siglo XX en las solicitudes de diversos particulares para atraer a familias de pescadores extranjeros a las costas chilenas, como en Maitencillo ${ }^{33}$ o Puerto Montt. ${ }^{34}$ Incluso, hay solicitudes que se extienden hasta 1962 con el fin de radicar a 35 familias italianas en el país. ${ }^{35} \mathrm{Si}$ bien estas peticiones resultaron ser proyectos y estudios para ver la posibilidad de una radicación definitiva, dan cuenta y entregan pistas que la intervención del Estado en la pesca artesanal permeó a otros actores, no solo sobre la idea de qué, cómo y cuándo pescar, sino también en la idea de quién puede hacerlo.

33 Pide en arrendamiento las playas que indica. Archivo Nacional de Chile, Ministerio de Industria y Obras Públicas, 10 de enero, 1910, Vol. 2253, f. 240.

34 Arriendo y conseción de playa de Puerto Montt. Archivo Nacional de Chile, Ministerio de Obras Públicas, 29 de noviembre, 1911, Vol. 2507 (s.f.).

35 Radicación de 35 familias italianas de pescadores en Chile. Archivo Nacional de Chile, Ministerio de Agricultura, 1962, Vol. 1517 (s.f.). 


\section{Agradecimientos}

Proyecto FONDECYT 1150331, "La 'tragedia de los comunes' en los mares y litorales de Chile central. Hacia una historia de las relaciones humanas con los ambientes y ecosistemas marinos y costaneros. s. XIX y XX".

\section{Referencias citadas}

Camus, P., Hidalgo, R., y Muñoz, E. (2016). Las disputas por el mar: bienes comunes, pescadores y pesca industrial. El caso de la caleta Cocholgüe en el litoral centro sur de Chile a mediados del siglo XX. Población \& Sociedad, 23(2), 35-58.

Camus, P. e Hidalgo, R. (2017). "Y serán desplayados”. Recorrido histórico sobre los bienes comunes, pescadores artesanales y control legal del litoral en Chile. Historia Critica, 63, 97-116.

Hardin, G. (1968). The Tragedy of the Commons, Science, $162,1243-1248$.

Harvey, D. (2004). El nuevo imperialismo: acumulación por desposesión. Socialist Register, 40, 99-129.

Mansfield, B. (2004). Neoliberalism in the oceans: 'rationalization, property rights, and the commons question. Geoforum, 35, 313-326.

March, H. (2013). Neoliberalismo y medio ambiente: una aproximación desde la geografía critica. Documents d’Anàlisi Geogràfica, 59(1), 137-153.

Ostrom, E. (1990). Governing the Commons: The Evolution of Institutions for Collective Action. Cambridge, MA: Cambridge University Press.

Thompson, E. P. (1995). Costumbres en común. Barcelona: Crítica.

\section{Fuentes citadas}

Archivo Nacional de Chile, Ministerio de Agricultura, Vol. 1517.

Archivo Nacional de Chile, Ministerio de Industria y Obras Públicas, Vol. 1697.

Archivo Nacional de Chile, Ministerio de Industria y Obras Públicas, Vol. 2253.

Archivo Nacional de Chile, Ministerio de Industria y Obras Públicas, Vol. 2448.

Archivo Nacional de Chile, Ministerio de Industria y Obras Públicas, Vol. 2518.

Archivo Nacional de Chile, Ministerio de Industria y Obras Públicas, Vol. 2733.

Archivo Nacional de Chile, Ministerio de Industria y Obras Públicas, Vol. 2804.

Archivo Nacional de Chile, Ministerio de Industria y Obras Públicas, Vol. 2990.

Archivo Nacional de Chile, Ministerio de Industria y Obras Públicas, Vol. 3190.

Archivo Nacional de Chile, Ministerio de Industria y Obras Públicas, Vol. 3217

Juzgado de Letras de Coquimbo, "Alfredo Meneses. Sobre accidente en pesca con explosivos", $\mathrm{N}^{\circ}$ de Caja 487, $\mathrm{N}^{\circ}$ de Expediente 12, 11.07.1918 / 12.09.1918.

Juzgado de Letras de Coquimbo, "Juan Ramos y Juan Cortés. Pesca con dinamita". $N^{\circ}$ de Caja 520, N de Expediente 21, 19.02.1920 / 30.08.1921.

Juzgado del Crimen de Antofagasta, "Maldonado Tabilo, José Segundo con Espinoza Juan de Dios. Sustracción de explosivos destinados a la pesca con dinamita", Caja $\mathrm{N}^{\circ}$ 41221, Número de Expediente 17, 22.11.1957 / 30.04.1958. 